\title{
Is Sciencey A Word?
}

A $s$ a new editor I have received a range of feedback about Ecological Restoration including the comment that our articles are too "sciencey." This word isn't in the dictionary, but it's a useful term. It describes a style of communication featuring specialized and technical language. People describe something as sciencey when it seems unnecessarily full of jargon ("that advertisement for a hoe is written in a very sciencey way"), but also when they don't connect to the material or understand it, and when it seems remote from practice and application.

Ecological Restoration has a long history of featuring articles with a range of goals including building the practice of restoring ecosystems, growing the scientific branch of restoration ecology and exploring the social, cultural and historical meanings of restoration. The sciencey comment challenges us to remember the importance of engaging with diverse topics and in accessible ways. Any area of knowledge has its own history and language, which interact to create and reinforce boundaries that can also be exclusive. As the ecological subfield of restoration science matures and expands, for example, its language necessarily becomes specialized and specific (as is argued for by contributor Joy Zedler in this issue).

Restoration is not only a branch of the discipline of ecology; it is also an economic enterprise, a social movement, an element of environmental education, an urban development issue, a tool for mitigating environmental problems, a social justice issue and more. How easily can one journal speak to participants of such widely spread endeavors? A fairly new concept, restoration is also a much-debated one as participants tug and pull the definition. There is a wide ranging discussion on the goals of the enterprise, and there is debate over how "successful" restoration can be.

In this swirl of ideas, it might be tempting to look for a core set of ideas that can serve as a touchstone. From my perspective, however, our general need for new ideas and techniques in order to solve environmental problems means that boundaries need to remain flexible and broader participation encouraged. The project is not one of bridging and integrating existing methods and approaches, but one of creating entirely new ways of thinking. There are many people involved in the important work of building and clarifying fundamental guidelines of restoration.

Ecological Restoration Vol. 25, No. 3, 2007

ISSN 1522-4740 E-ISSN 1543-4079

(O2007 by the Board of Regents of the University of Wisconsin System.
Ecological Restoration, in contrast, provides a forum for many different ideas, perspectives and specialties. I see a continued need to educate and inspire a diverse group of people-an argument, perhaps, for the power of synergy over sciencey.

One useful technique for integrating complex and diverse types of information is to focus on story telling. Much has been said about the power of narrative, and of the fundamental role of story telling in shaping how we understand the world around us and how we determine what we believe to be the truth. William Cronon has written about narratives of historical environmental change, for example, and has argued that while nature does not tell a story, humans are very much inclined to organize reality according to stories, which he defines as a series of actions with a beginning, middle and, importantly, an end. This end often carries moral import ("A Place for Stories: Nature, History, and Narrative" The Journal of American History March 1992: 1368). While I don't agree with Cronon's confident dismissal of nature's story telling, I do agree that it is very appropriate for all of us to be more self conscious about the stories that we tell-especially when we are doing our science- - and how those stories shape how and why we pursue and share knowledge. Furthermore, these stories help create a sense of urgency and context, so that even very technical information (especially if presented in plain language) can be more accessible to a broad range of readers.

This issue contains some great stories. Jason Evans and his colleagues interviewed long-time residents about their understanding of invasive plants and ecological change in Kings Bay, Florida. This resulting story, along with a review of scientific research, led the authors to suggest a radically different approach to ecological management of the Bay, which is home to a population of endangered manatees. The approach to restoration they offer is informed not only by the work of ecologists, but also by local residents who have the benefit of decades of observation in the area.

Chris Obropta and Peter Kallin tell their story about a multi-year collaborative restoration project in Rahway, New Jersey. They lay out some of the many details that engaged them as they created a green jewel of a nature park in place of deteriorating urban housing. This effort was complicated in many ways. Peter Kallin told me, for example, that in New Jersey, having the head of tide line on your property means that the U.S. Army Corps of Engineers regulates one side of the line and the state's environmental protection 
agency regulates the other-meaning you need twice as many permits for restoration work. Labor for the project came not only from hired contractors and the county, but also from participating schools, Boy Scout troops, and even jails. In the end, Obropta and Kallin deem the effort a great success, both because of the new park and because of the many different people who collaborated.

Speaking of success, in her piece in this issue, Joy Zedler suggests that we clarify the terms we use in stories about the work of restoration. Zedler reminds us that the term success depends on the eye of the beholder. She acknowledges the pressures that exist on restorationists to reassure people that goals have been met with "success," and she makes the argument that given these pressures it is critical that we develop mutually agreed on, science-based evaluation measures for our efforts.

Rosemary Bush and her colleagues describe a study investigating the recolonization of native grassland plants in Colorado following the eradication of diffuse knapweed using insect control. These researchers found that although native perennial forbs did increase in cover, species richness was unchanged. Their conclusion: the reduction of a regionally abundant, non-native plant species alone is not sufficient to restore a formerly dominant native plant species.

Peter Lesica and Helen Atthowe report on a study to identify strains of native bluebunch wheatgrass that might be genetically resistant to invasive spotted knapweed. Their results suggest that selecting for vigor and productivity among a large number of wild, local native plants may be the best way to develop restoration cultivars that tolerate and suppress invasive weeds.

In addition, Eric Stone shares some insights into how the scale and duration of restoration efforts can influence small mammal populations. A major goal of his research is to inform restoration at the Rocky Mountain Arsenal in Colorado. The U.S. Army manufactured chemicals and explosives at RMA between 1942 and 1949, and the Shell Chemical Company produced insecticides, herbicides, caustics, adhesives, and lubricants for many years until 1982. Early waste-disposal and transportation methods involved unlined natural depressions as evaporation ponds and unlined open ditches, resulting in significant soil and ground water contamination. Stone's field sites were not contaminated, but his goal is to inform RMA restoration efforts, some of which involve not only intensive soil and plant disturbance, but also extensive areas.

I am very pleased to present these research results and stories. As always, if you have any questions or comments please contact me at mingram@wisc.edu. Letters to the editor are most welcome. In addition, you can visit our website at www.ecologicalrestoration.info in order to preview the upcoming issue, read some restoration news, and view our innovations gallery, currently featuring an aspen girdling tool made from a butter knife. Many thanks to Art Levy for making the website happen.

Finally, I would like to pay tribute to Ecological Restoration's associate editor Mary Ann Pels, who passed away in July. As many of you who have been with us for a while know, Mary Ann is a piece of this journal's foundation. Her tenure, beginning with Bill Jordan in 1998, spanned three editors. She worked with many, many authors, improving notes and book reviews and copyediting articles. Although I had the pleasure of working with her for only a few months I was deeply impressed with her commitment and excitement about the journal and her knowledge of the networks of people involved in restoration. Mary Ann was also smart, funny, and not afraid to share an opinion. She and I spoke a great deal about a revitalization of the Notes in the journal, including inviting a wider variety of submissions and creating a special section up front in order to highlight the nitty-gritty work of ecological restoration, including the cutting edge, the ongoing, and the off-thewall. I am very sad not to be able to embark on this effort with her, but her good ideas will help make this a reality in the future. Mary Ann blessed all of us at the Arboretum with a warm, giving, and graceful presence and I know I speak for many when I say that although we are bereft, we feel fortunate to have known her.

Mrill Ingram

Editor 